\title{
KEF-conference takes critical look at the role of re- search in achieving the MDGs
}

Karin Chladek

A conference hosted by the Commission for Development Studies (KEF) at the Austrian Academy of Sciences (OeAW) on 29 November 2005 in Vienna invited Austrian and international scientists to take a critical look at the role of research in achieving the UN-Millennium Development Goals (MDGs). With this event KEF has started an ongoing critical reflection process within the Austrian scientific development community on the actual and possible contributions of North-South-research partnerships to the MDGs, with a special focus on „pro-poor-research“.

"Considering the MDGs in the context of North-South research partnerships is not only a moral demand, it is also becoming a very important argument for acquiring funds", KEF-co-ordinator Birgit Habermann stressed in her opening speech.

\section{Lack of a common strategic goal and in- dicators}

The participants of the conference, among them many active researchers and high-ranking development experts both from Austria and the international field, discussed how effectively research partnerships between Austrian institutions and partner universities in countries of the global South can contribute to achieving the MDGs. On the one hand, attention was drawn to an obvious lack of a common strategic goal and framework of all North-South research partnerships initiated or supported by Austria - a factor of utmost relevance to achieving aims such as the MDGs. On the other hand, researchers criticized the lack of indicators (or a system of indicators) that could enable them to monitor the contribution of their work to the MDGs.

\section{Research as integrative part of develop- ment}

"Research must be understood as integrative part of development and therefore also of development cooperation", Hannah Akuffo stated. Ms. Akuffo, Deputy Head of the Division for University Support and National Research in the Department for Research Co-operation (SAREC) at the Swedish International Development Agency (SIDA), presented an overview of the activities and long-term strategy of North-South research partnerships in the Swedish context. Sweden has been one of the most consistent donor countries for years, reserving $1 \%$ of the Gross National Product for development co-operation projects (Austria reserved only $0,24 \%$ of the Gross National Product for development co-operation in 2004). This fact, and the long-term strategy that Swedish support is based on, make consistent work possible, Hannah Akuffo underlined. The budget Sweden has recently reserved for research co-operation projects in Africa equals 320 million Swedish Crowns (33.6 million Euro) per year, projects in Latin America and Asia received an allocation of a further 90 million Swedish Crowns (9.5 million Euro) respectively.
Olivia la O' Castillo, board member in UN Sec.Gen. Kofi Annan's Water \& Sanitation Advisory Board and Chair/ President/ Founding Member of the Asia Pacific Roundtable for Sustainable Consumption \& Production, took a closer look at South East Asia and stressed the importance of gender equality in education, employment and political life (MDG No. 3). In her opinion, scientific cooperation projects should put more emphasis on education and teacher training on different levels, with a special focus on women's empowerment.

Wolfgang Lutz, director of the Vienna Institute of Demography and leader of the World Population Program of the International Institute for Applied Systems Analysis (IIASA), presented the eight MDGs and introduced the computer simulation model PEDA as an example for research about development. According to PEDA simulations, only a combined approach of consistent and better education and training, especially for women, new technology and a decline of population growth will lead to a stable condition with less poverty and hunger. This is especially valid for some of the poorest African countries.

\section{Workshop on case studies}

After the presentations several working groups studied and discussed recent North-South research partnerships with Austrian commitment and their actual or possible contribution regarding the MDGs. The projects presented embraced e.g. the impact of irrigation on poverty and environment in Ethiopia, river ecology and social factors in Sri Lanka, or forest ecology and local knowledge in Bhutan. It became evident that the scientific community in Austria strives for further discussion, reflection and regular interchange on the topics with their partners in developing countries and vice versa. KEF is ready to serve as a platform and contact point. However, one of the main tasks will be to shift the focus of the debate away from the Austrian Scientific community towards researchers in developing countries.

\section{A more focussed approach of research for development}

In his closing speech Gerhard Glatzel, Chair of KEF and Head of the Institute for Forest Ecology at the University of Natural Resources and Applied Life Sciences in Vienna, called for a strategic focussing of research for development in Austria. "Surely it would make sense to allocate a part of the promised enlarged budget for development co-operation to a more focussed approach of research for development. There have been very dedicated and fruitful research partnerships between Austrian scientists and partners from the global South already, but there also is a constant lack of common strategy and political commitment. Scientists struggle with a lack of support and a long-term, institutionalized framework. A focussed approach would be a big step forward - also with regards to the Millennium Development Goals." 